\title{
Novel Gene Variants Predict Serum Levels of the Cytokines IL-18 and IL-1ra in Older Adults
}

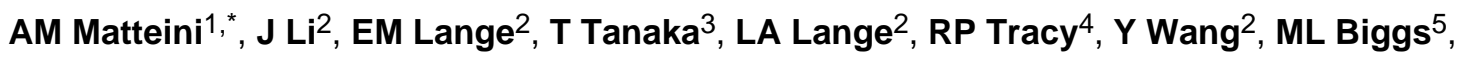 \\ DE Arking ${ }^{6}$, MD Fallin $^{7}$, A Chakravarti ${ }^{6}$, BM Psaty ${ }^{8,9}$, S Bandinelli $^{10}$, L Ferrucci ${ }^{3}$, AP \\ Reiner $^{11}$, and JD Walston ${ }^{1}$ \\ ${ }^{1}$ Division of Geriatric Medicine, Johns Hopkins Medical Institution, Baltimore, MD \\ ${ }^{2}$ Department of Genetics, University of North Carolina, Chapel Hill, NC \\ ${ }^{3}$ Translational Gerontology Branch, Intramural Research Program, National Institute on Aging, \\ Bethesda, MD \\ ${ }^{4}$ Departments of Pathology and Biochemistry, University of Vermont College of Medicine, \\ Burlington, VT \\ ${ }^{5}$ Department of Biostatistics, University of Washington, Seattle, WA \\ ${ }^{6}$ McKusick-Nathans Institute of Genetic Medicine, Johns Hopkins University School of Medicine, \\ Baltimore, MD \\ ${ }^{7}$ Department of Epidemiology, Johns Hopkins Bloomberg School of Public Health, Baltimore, MD \\ ${ }^{8}$ Cardiovascular Health Research Unit, Departments of Medicine, Epidemiology, and Health \\ Services, University of Washington, Seattle, WA \\ ${ }^{9}$ Group Health Research Institute, Group Health Cooperative, Seattle, WA \\ ${ }^{10}$ Geriatric Unit, Azienda sanitaria firenze, Florence, Italy \\ ${ }^{11}$ Departments of Medicine, Epidemiology and Genome Sciences, University of Washington, \\ Seattle, WA
}

\section{Abstract}

Activation of inflammatory pathways measured by serum inflammatory markers such as interleukin-18 (IL-18) and interleukin-1 receptor antagonist (IL-1ra) is strongly associated with the progression of chronic disease states in older adults. Given that these serum cytokine levels are in part a heritable trait, genetic variation may predict increased serum levels. Using the Cardiovascular Health Study and InCHIANTI cohorts, a genome-wide association study was performed to identify genetic variants that influence IL18 and IL-1ra serum levels among older

(C) 2013 Elsevier Ltd. All rights reserved.

*Corresponding Author, Amy M. Matteini, PhD, 2024 East Monument Street, Suite 2-726, Baltimore, Maryland 21205 USA, +1 410 502 4331, amatteini@jhmi.edu.

Publisher's Disclaimer: This is a PDF file of an unedited manuscript that has been accepted for publication. As a service to our customers we are providing this early version of the manuscript. The manuscript will undergo copyediting, typesetting, and review of the resulting proof before it is published in its final citable form. Please note that during the production process errors may be discovered which could affect the content, and all legal disclaimers that apply to the journal pertain. 
adults. Multiple linear regression models characterized the association between each SNP and logtransformed cytokine values. Tests for multiple independent signals within statistically significant loci were performed using haplotype analysis and regression models conditional on lead SNP in each region. Multiple SNPs were associated with these cytokines with genome-wide significance, including SNPs in the IL18-BCO gene region of chromosome 2 for IL-18 (top SNP rs2250417, P $=1.9 \times 10^{-32}$ ) and in the $I L 1$ gene family region of chromosome 2 for IL-1ra (rs6743376, P = $\left.2.3 \times 10^{-26}\right)$. Haplotype tests and conditional linear regression models showed evidence of multiple independent signals in these regions. Serum IL-18 levels were also associated with a region on chromosome 2 containing the $N L R C 4$ gene ( $r$ 12989936, $\left.\mathrm{P}=2.7 \times 10^{-19}\right)$. These data characterize multiple robust genetic signals that influence IL-18 and IL-1ra cytokine production. In particular, the signal for serum IL-18 located on chromosome two is novel and potentially important in inflammasome triggered chronic activation of inflammation in older adults. Replication in independent cohorts is an important next step, as well as molecular studies to better understand the role of NLRC4.

\section{Keywords}

chronic inflammation; genome-wide association studies; older adults

\section{Introduction}

Chronic activation of inflammatory pathways as measured by serum inflammatory markers is strongly associated with the progression of chronic disease states, sarcopenia, frailty, and mortality in older adults (1). Increased fat tissue, senescent cells, chronic disease states, damaged mitochondria, and genetic variation all likely play a role in triggering chronic activation in inflammatory pathways (1). Nuclear factor $\kappa B(N F-\kappa B)$ is a nuclear receptor that functions as a gateway molecule for inflammatory pathway signaling, and most of the serum measures of inflammation previously utilized in studies of human subjects are influenced by its activity (1). Of the commonly measured serum markers of inflammation, interleukin 18 (IL-18), and interleukin-1 receptor antagonist (IL-1ra) are among the 5 best predictors of 10 year mortality in a longitudinal cohort study of community dwelling older adults (2). IL-1ra and IL-18 are part of the IL-1 family of cytokines that are generated very early in the inflammatory signaling process, and are thought to be important mediators of inflammation and the aging process(3).

Beyond their association with accelerated mortality in older adults, epidemiological studies show that increased IL-18 levels are strongly associated with insulin-resistance in diabetic and non-diabetic individuals, as well as type-II diabetes and a number of other metabolic risk factors (4,5). A recent meta-analysis of prospective data concluded that serum IL-18 is a strong predictor for cardiovascular disease, independent of the effects of IL-6 and CRP (6). Similarly, IL-1ra concentrations have been independently associated with metabolic syndrome (7). Mice deficient in IL-1ra develop a chronic inflammatory state leading to autoimmune arthritis (8). Both IL-18 and IL-1ra levels are associated with uric acid levels and are thought to be important in adipose tissue-driven inflammatory signaling $(9,10)$. 
In addition to these associations between serum levels of IL-1ra and IL-18 and adverse health outcomes, there are several reported associations between polymorphisms within the genes encoding IL-18 and IL-1ra and aging-related conditions. The ILIRN gene encoding IL-1ra is located within a $\sim 30 \mathrm{~kb}$ IL-1-related gene cluster on chromosome $2 \mathrm{q} 13-21$ that also contains the genes for IL-1B and IL-1A (11). Variations in this IL-1 gene cluster have been linked to a number of inflammatory conditions including lupus, vasculitis, renal failure, cognitive decline, and cardiovascular disease $(12,13)$. IL-1ra expression is driven by AP-1, which is stimulated by the early inflammatory mediator IL-1B $(14,15)$. IL-18 is encoded by a $19.5 \mathrm{~kb}$ gene (IL18) located on chromosome 11q22-11q23 (16). Variation in IL18 has been shown to correlate with adverse cardiac and other health outcomes (17). Using subjects from the InCHIANTI cohort, Melzer et al identified polymorphisms in ILIRN and IL18 that influence serum levels of the respective gene protein products (18). Additional GWA studies of variation in interleukin serum levels in small cohorts have yielded similar results $(19,20)$ (21), but were most likely underpowered to pinpoint multiple independent signals within the regions or to characterize weaker signals in other parts of the genome that influence these important inflammatory serum levels in older adults. Given the importance of these proteins in inflammatory signaling, and prior knowledge that serum cytokine levels are in part a heritable trait, we hypothesized that genetic variation predicts increased serum levels of IL-18 and IL-1ra in older adults, and sought to identify gene variants that influence serum levels of these important inflammatory mediators in a large population of older adults (22).

\section{Subjects and Methods}

\subsection{Subjects}

The Cardiovascular Health Study (CHS) is a prospective observational cohort study designed to characterize risk factors of cardiovascular disease in older adults. The study recruited 5,888 men and women over the age of 65 at baseline based on age- and genderstratified samples from Medicare eligibility lists from four field centers across the United States between 1989 and 1990. Details of sampling and exclusion criteria have been published elsewhere (23). For the purpose of this study, only samples from Caucasian participants were used. African Americans were excluded from analysis. The participants for this study included 3233 European Americans from the CHS cohort with biomarker phenotypes and GWAS data and who provided informed consent for genetic analyses at the time of blood draw. InCHIANTI is a prospective population-based cohort study of the factors that contribute to mobility decline in older Italian adults. The study sample $(1,210$ Caucasian participants aged 65-102 years) was randomly selected using a multistage stratified sampling method from two towns in the Chianti geographic area of Italy (Greve in Chianti and Bagno a Ripoli, Tuscany, Italy). The details of the data collection and sampling procedures have been described elsewhere (24). All participants gave written consent for study participation at the time of blood draw and the Italian National Research Council of Aging Ethical Committee approved the study.

\subsection{Cytokines}

Cytokines were measured from stored serum drawn at the baseline visit in both cohorts. For CHS participants, IL-1ra and IL-18 were measured by the Mesoscale chemiluminiscent 
multiplex system. The human 2-plex kits were purchased from MSD (Mesoscale Discovery Technology (MSD), Gaithersburg, MD USA). SULFO-TAG ${ }^{\mathrm{TM}}$ Human IL-18 Detection Antibody and Biotinylated Human IL-1ra Detection Antibody were used for the assay. MSD plates were measured on the MSD Sector Imager 2400 plate reader. The raw data was measured as electrochemiluminescence signal (light) detected by photo detectors and analyzed using the Discovery Workbench 3.0 software (MSD). A 4-parameter logistic fit curve was generated for each analyte using the standards and the concentration of each sample calculated. The kit's sensitivity is $0.6 \mathrm{pg} / \mathrm{ml}$ for IL-18 and $1.2 \mathrm{pg} / \mathrm{ml}$ for IL- $1 \mathrm{ra}$. In the InCHIANTI population, IL-1 RA was measured by ELISA using a commercial kit (BIOSOURCE international, Camarillo, CA). Serum IL-18 was measured using highly sensitive quantitative sandwich assays (Quantikine HS, R\& D systems, Minneapolis, MN). Assay precisions and detectable limits were reported previously (25-27).

\subsection{Genotyping}

Genotyping in the CHS population was carried out using the Illumina 370CNV chip and genotype calls were done using Bead-Studio software, resulting in 307,655 genotyped SNPs. SNPs were retained for analysis using a call rate greater than 0.95 and Hardy-Weinberg equilibrium p-value $21 \mathrm{E}-5$. Imputation to HapMap Phase II and III (CEU reference samples) was performed using $\mathrm{MaCH} 2.0 \mathrm{~V}$ software, resulting in 2,543,887 and 1,387,466 SNPs respectively. In InCHIANTI, genotyping was performed with the Illumina Infinium HumanHap550 genotyping chip (chip versions 1 and 3) as previously described (19).

Using GWAPower software, power calculations were performed to assess the difference in power of the combined InCHIANTI-CHS meta-analysis compared to single study analyses, assuming linkage disequilibrium $\left(\mathrm{r}^{2}\right)$ of 0.5 between a SNP and putative causal variant and $10 \%$ variance explained by the twelve covariates (Feng S, 2011 BMC Genetics). The power analysis demonstrated the InCHIANTI cohort $(n=1,200)$ to have adequate power $(0.85)$ to detect a true association with serum interleukin levels at $\mathrm{h}^{2}=0.03$. The CHS population $(\mathrm{n}=$ $3,200)$ demonstrated sufficient power $(0.99)$ at $h^{2}=0.02$. At the lowest effect size $\left(h^{2}=\right.$ 0.01 ) neither InCHIANTI nor CHS alone have adequate power to detect a true association with serum interleukin levels ( 0.05 and 0.74 , respectively). The combined InCHIANTI-CHS meta-analysis achieved $>95 \%$ power across all effect sizes $\left(h^{2} \geq 0.01\right)$. Although these estimates indicate that either the InCHIANTI and CHS cohort has sufficient power to independently detect a true association at small effect sizes $\left(h^{2}=0.03\right)$, the smallest effect sizes may only be uncovered with larger sample sizes $\left(h^{2} \leq 0.01\right)$. As demonstrated in Table 1, sample sizes similar to those in previously published GWA studies of IL-18, (i.e., $\mathrm{n}=$ 700) may have been underpowered to detect smaller effect SNP associations.

\subsection{Statistical analysis}

Serum IL-1ra and IL18 levels were log-transformed for approximate normalization. Multiple linear regression models were built for each serum marker separately and analyzed using PLINK (http://pngu.mgh.harvard.edu/purcell/plink/) (28-30), with covariate adjustment for age, gender and the first 10 principal components reflecting background ancestry. SNPs were modeled assuming additive effects. GWAS analyses were performed in the CHS and InCHIANTI cohorts separately. Then, inverse variance weighted meta-analysis was 
performed in METAL (31) software using a fixed-effects model of beta coefficients and standard errors from CHS and InCHIANTI. Genome-wide significance was defined as a pvalue less than $5 \times 10^{-8}$.

Regions of interest from the GWAS results were further examined with haplotype and conditional analyses using the CHS population only. Multivariable regression models were built that included the most strongly associated SNP as a covariate to determine whether there were multiple independent association signals in a particular region. Region-specific plots were made to show the magnitude of association between all SNPs as well as the linkage disequilibrium (LD) between each SNP in the region and the most strongly associated SNP. Haplotype analyses were conducted using Haplo.stat (32), to examine specific combinations of allelic variants and whether the observed association signal is likely attributable to a less common unmeasured genetic variant (9). The 'haplo.glm' function implemented in the 'haplo.stats' R package was used to calculate beta coefficients $(\beta)$, standard errors (SE) and P-values for each haplotype relative to the most common reference haplotype. The 'haplo.score' function implemented in the 'haplo.stats' R package was used to calculate the global score statistics to test the overall association between haplotypes and biomarker levels. Finally, to help interpret the relationship between the haplotype results and the unconditional and conditional association results from nongenotyped imputed SNPs, we downloaded genotype data from CEU HapMap samples and used the 'haplo.em' function to construct complete haplotypes in the regions of interest. Specifically, we used these data to identify which haplotypes in our haplotype analyses were expected to carry the minor allele for the top imputed SNPs that were identified in our individual SNP analyses.

\section{Results}

Descriptive statistics for the CHS and InCHIANTI samples are shown in Table 2. Q-Q plots for genome-wide SNP associations revealed no substantial evidence for inflated results due to population stratification, residual relatedness among subjects or experimental effects (not shown). Manhattan plots from the CHS analysis demonstrate 2 regions of genome-wide significance for plasma IL18 and one region for IL-1ra (Figures 1A,1B). Overall, there were 209 genome-wide significant SNPs for the IL-18 outcome (175 SNPs on chromosome 2 and 34 SNPs on chromosome 11) and 116 hits for IL-1ra (all SNPs on chromosome 2). The top SNPs for each outcome are listed in Tables 2 (IL-18) and 3 (IL1-RA). Manhattan plots for the InCHIANTI analysis were similar (not shown).

\subsection{Interleukin-18 GWAS Results- Chromosome 11}

All top SNPs on chromosome 11 associated with IL-18 clustered within a region spanning less than $70 \mathrm{~kb}$ containing 3 genes: IL18, TEX12, and BCO2. The strongest signal (rs10891343 [imputed], $\mathrm{P}_{\mathrm{CHS}}=7.3 \times 10^{-20}, \mathrm{P}_{\mathrm{InCH}}=7.9 \times 10^{-13}$ and rs 2250417 [genotyped], $\mathrm{P}_{\mathrm{CHS}}=9.6 \times 10^{-20}, \mathrm{P}_{\mathrm{InCH}}=1.3 \times 10^{-13}$ mapped to the $B C O 2$ gene, which encodes betacarotene oxygenase 2 . SNPs within the IL18 gene were also highly significant (Table 3). In CHS, after conditioning on rs10891343, the remaining significant SNPs were no longer genome-wide statistically significant $\left(\mathrm{P}_{\mathrm{CHS}}<5 \times 10^{-8}\right)$; however, several SNPs in the intronic 
region of IL18 had nominally significant evidence that was not observed in the marginal single SNP tests, particularly SNP rs795467 $\left(\mathrm{P}_{\mathrm{CHS}}=0.17\right.$ in the marginal test and $\mathrm{P}_{\mathrm{CHS}}=$ $1.1 \times 10^{-4}$ in the conditional test). This observation suggests multiple associated loci or an underlying haplotype effect.

Haplotype analyses in CHS using genotyped SNPs further supported the single SNP and conditional SNP analyses. SNP rs2250417 was used to represent the index SNP and any other SNPs in LD with that SNP from the Illumina 370CNV array located within $500 \mathrm{Mb}$ were then considered. Evaluation of HapMap CEU haplotype data confirmed the combination of rs1946518, rs5744222 and rs2250417 tagged separate common haplotypes in the region. SNPs rs5744222 and rs2250417 flank index SNP rs10891343 and places the minor allele of rs 10891343 onto two separate haplotypes; rs 1946518 splits the most common haplotype, which harbors the major allele for rs10891343. Frequency and effect size estimates for these haplotypes on log-transformed IL-18 serum levels are shown in Table 4 . There was significant evidence for an overall association between haplotypes and IL-18 levels $\left(\mathrm{P}_{\mathrm{CHS}}<0.0001\right)$. Both H2 (T-G-C, freq=0.26) and H3 (G-T-C, freq=0.25) haplotypes were significantly associated with lower IL-18 levels compared with the most common haplotype (G-G-T), with $\mathrm{P}_{\mathrm{CHS}}$ values of $8.4 \times 10^{-7}$ and $1.0 \times 10^{-16}$, respectively (Table 4). A post hoc comparison of these two haplotypes showed that their haplotypic effects were significantly different $\left(\mathrm{P}_{\mathrm{CHS}}=3.8 \times 10^{-6}\right)$. Based on HapMap CEU data, the minor allele for our top imputed SNP rs10891343 rests on both H2 and H3. Interestingly, SNP rs795467, which became nominally significant in the conditional SNP analysis after conditioning on rs10891343, sits entirely on the H2 haplotype.

\subsection{Interleukin-18 GWAS Results: Chromosome 2}

The remaining 175 top $I L 18$ SNPs clustered within an $8.8 \mathrm{Mb}$ region of chromosome 2 (Table 3), containing six genes: SRD5A2, MEMO1, DPY3O, SPAST, SLC3OA6 and NLRC4, with the strongest evidence of association located between DPY3O and SPAST genes (rs12989936 [imputed], $\mathrm{P}_{\mathrm{CHS}}=2.5 \times 10^{-15}, \mathrm{P}_{\mathrm{InCH}}=4.5 \times 10^{-5}$. Linkage disequilibrium in the region is very high (Supplementary Figure 1) and in CHS, after conditioning on rs12989936, the remaining 174 SNPs in the region no longer showed genome-wide statistical significance $\left(\mathrm{P}_{\mathrm{CHS}}<5 \times 10^{-8}\right)$, though $\mathrm{rs} 6543646\left(\mathrm{P}_{\mathrm{CHS}}=2.6 \times 10^{-5}\right)$, a rare imputed variant (minor allele frequency $[\mathrm{MAF}]=0.009$ in HapMap CEU) which is located in the intron region between $D P Y 30$ and SPAST, demonstrated nominal evidence for association. The association effect estimate for rs12989936 was consistent with additive effects.

Haplotype analyses were performed in an attempt to further characterize the association signal in the region. Since the best SNP signal (rs12989936) was imputed, directly genotyped rs212713 was used as a proxy in haplotype analyses $\left(r^{2}=0.66, D^{\prime}=0.95\right.$ in HapMap CEU samples). Genotyped SNPs rs7559329 and rs10084280 were used for haplotype construction together with rs212713 based on evaluation of HapMap haplotype data (ordered: rs7559329, rs10084280 and rs212713). There was significant evidence for an overall association between chromosome 2 haplotypes and IL-18 levels (Table 5) $\left(\mathrm{P}_{\mathrm{CHS}}<\right.$ 0.00001). Haplotypes H1, H2 and $\mathrm{H} 4$ were all significantly associated with lower IL-18 levels compared to the most common haplotype $\mathrm{H} 5$ ( $\mathrm{P}_{\mathrm{CHS}}$ of $1.8 \times 10^{-7}, 0.0090$ and 
$7.5 \times 10^{-9}$, respectively). The effect for haplotype $\mathrm{H} 3$ was not significantly different than baseline haplotype $\mathrm{H} 5\left(\mathrm{P}_{\mathrm{CHS}}=0.13\right)$ and no significant difference were observed between the contrasts for the effect estimates for H1, H2 and H4 (data not shown). Based on HapMap CEU data, the minor allele for the top SNP, rs12989936, rests primarily on both $\mathrm{H} 1$ and H4, while the minor allele for the rare imputed variant, rs6543646, rests on both $\mathrm{H} 2$ and baseline haplotype H5.

\subsection{Interleukin 1-receptor antagonist GWAS Results: Chromosome 2}

There were 116 SNPs significantly associated with IL-1ra serum levels all of which were located in a $58 \mathrm{~kb}$ region of chromosome 2 of the IL1 gene family. Top hits were found for SNP rs6743376 $\left(\mathrm{P}_{\mathrm{CHS}}=2.0 \times 10^{-21}, \mathrm{P}_{\mathrm{InCH}}=2.3 \times 10^{-5}\right.$, and rs6761276 $\left(\mathrm{P}_{\mathrm{CHS}}=4.2 \times 10^{-21}\right.$, $\mathrm{P}_{\mathrm{InCH}}=4.5 \times 10^{-6}$, both imputed missense mutations in the IL1F10 gene, coding Ala51Asp and Ile44Thr protein changes, respectively (Table 6). These loci are highly correlated $\left(\mathrm{r}^{2}=0.74, \mathrm{D}^{\prime}=1.0\right.$, HapMap CEU samples). In the CHS cohort after conditioning on the rs6743376 signal, 55 SNPs were significantly associated with IL-1ra, particularly in the 47 $\mathrm{kb}$ region between the ILIFIO and ILIRN genes (Best SNP: rs11687782 [imputed], $\mathrm{P}_{\mathrm{CHS}}=$ $1.2 \times 10^{-12}$ ) and the $I L 1 R N$ gene itself (Best SNP: rs431726 [imputed], $\mathrm{P}_{\mathrm{CHS}}=3.57 \times 10^{-9}$ ).

All associated SNPs in the ILIRN gene were intronic, with the exception of rs419598 which is a synonymous mutation. This evidence suggests that multiple loci from the ILIFIO and $I L I R N$ genes as well as the surrounding region are associated with differences in IL-1ra plasma levels.

Haplotype analysis in CHS provided additional insight into the underlying association signals in the $I L I R N$ gene region. Six haplotypes with frequencies greater than 0.02 were observed based on three-SNP haplotypes containing genotyped SNPs: rs2515402, rs6759676 and rs1542176. Four haplotypes (H1, H2, H4 and H5) were significantly associated with higher levels of log-transformed IL-1ra levels compared to baseline haplotype $\mathrm{H6}$ (Table 7). Haplotype $\mathrm{H} 2$ had significantly stronger effects $\left(\mathrm{P}_{\mathrm{CHS}}<0.05\right.$ for all contrasts) than the other positively associated haplotypes. The minor alleles for rs 6743376 and rs6761276 were both predicted to be on haplotypes H1, H2, H3, and H4. The T allele for rs11687782, the top significantly associated SNP after adjusting for rs6743376, resides primarily on haplotypes $\mathrm{H} 2, \mathrm{H} 4$ and $\mathrm{H} 5$ according to HapMap CEU data, while the A allele rests on H1, H3 and H6. Thus, rs11687782 effectively separates H5 from H6 and captures the unexplained (with respect to rs6743376 and rs6761276) association for H5. The genotypes for the other imputed SNP with evidence in the conditional analyses, rs431726, also split H5 and H6.

\section{Discussion}

In a GWAS study of older adult Caucasians, we have identified multiple SNPs associated with serum inflammatory mediators IL-18 and IL-1ra, including a novel region on chromosome 2 associated with IL-18 serum levels. In addition, this study confirms and extends previously identified genetic signals related to IL-18 and IL-1ra serum, including fine-mapping and identification of multiple SNPs within the $I L I$ gene cluster that are independently associated with IL-1ra levels. The newly identified IL-18 association signal 
spans $8.8 \mathrm{Mb}$ and 5 genes including SRD5A2, DPY30, SPAST, SLC30A6, and NLRC4. Of these five genes, NLRC4 is the most likely to be related to inflammation given it codes for a platform protein that acts to assemble the inflammasome, a cluster of proteins reflecting very early responders to inflammatory stimuli (33). NLRC4 is initially responsive to gut pathogens and to flagellin (33). It then activates IL-18 and IL-1B through caspase-1 dependent mechanisms and likely also triggers apoptosis in the absence of caspase-1 autoprocessing $(33,34)$. SNPs rs479333 and rs 212713 are located within the intron of the NLRC4 gene and are significantly associated with serum levels of IL-18 (Table 2). However, other SNPs within that region are also highly associated with IL-18 and are in high linkage disequilibrium, making it difficult to pinpoint the locus that is most influencing the serum levels of IL-18. Given that the other genes in this region are not related to inflammatory pathway activation or inflammatory gene regulation, the NLRC4 gene variants seem the most likely to influence IL-18 serum levels through variation in inflammasome activity and hence cleavage and activation of IL-18. Future work of the NLRC4 region, including fine mapping and sequence analysis, should be done to better understand which SNPs are associated with serum IL-18 at this locus.

Previous GWAS and candidate gene studies have identified a significant association between serum IL-18 levels and SNPs within the IL18-BCO gene region (20,35-37). Top SNPs in these studies were consistent with top SNPs in our study, although it should be noted that two of the studies were previously performed in the InCHIANTI population, which was also included in this analysis. Ultimately, haplotype analyses with denser SNP panels, direct sequencing and functional analyses will be required to localize the causal variants in this region (38).

Two independent loci associated with IL-1ra serum levels were localized to chromosome 2 in the ILI gene cluster. First, two missense variants (Ala51Asp and Ile44Thr) in the ILIFIO gene were significantly associated with increased serum IL-1ra in both the CHS and InCHIANTI populations. These polymorphisms are common and in high LD with each other. The association of IL-1ra serum levels with IL1F10 SNPs rs6761276 and rs6734238 was suggestive, but did not reach genome-wide significance, in a prior GWAS in 1,200 whites from InCHIANTI (18) or 700 African Americans (26). Second, when these ILIF10 polymorphisms were controlled for, an independent significant association was observed between intronic SNPs in the ILIRN gene and increased serum IL-1ra. This signal was also observed in the haplotype analysis, which showed a distinct haplotype not containing the risk alleles for either rs6761276 or rs6734238 that was associated with increased IL-1ra levels. In prior candidate gene analyses of $I L I R N$ from InChianti (39) and a meta-analysis of 3 European studies (40), another common variant of $I L I R N$, tagged by the minor $\mathrm{C}$ allele of rs4251961 was associated with lower IL-1ra levels. In additional analyses that included both CHS and InChianti, the IL-1ra-lowering rs4251961 C allele was associated with higher plasma levels of several inflammation-sensitive biomarkers, including fibrinogen and Creactive protein $(39,41-43)$.

The function of the ILIFIO gene, recently renamed IL-38, is still largely unknown. However, ILIF10 shares about $40 \%$ homology with the ILIRN gene and is thought to play a role in inflammatory processes (44). Ala51Asp and Ile44Thr are located in the third exon of 
IL1F10. Using the prediction algorithm PolyPhen2 (45) neither amino acid substitution is predicted to alter protein structure/function. Two alternatively spliced transcript variants encoding ILIF10 protein have been reported, which differ in amino acid sequence between residues 9 and 39 due to an alternative splicing event that involves exon 3 . Therefore, it is possible that one or both of these exonic variants influence the relative amounts of alternative isoforms. Polymorphisms in both the ILIRN and ILIFIO genes have also been implicated in variation in serum CRP levels $(46,47)$. These signals are most likely altering the expression of the IL-1ra protein, although further research is needed to understand the exact mechanism.

Our results are therefore consistent with the existence of allelic heterogeneity within the ILI family gene cluster and genetic complexity underlying the regulation of IL-1ra and production of other acute phase proteins. Several in vitro studies have confirmed an effect of the rs4251961 variant on ILIRN gene transcription or IL-1ra production in immunestimulated cells (41). The rs4251961 variant is adjacent to a predicted GATA-1 transcription factor binding site within the $I L I R N$ promoter. Co-transfection experiments suggested that GATA-1 increases transcription from the ILIRN promoter, and may act differentially depending upon rs4251961 genotype (48).

In summary, we report detailed genetic association findings generated from two large prospective cohorts of older adults regarding genetic influences on proinflammatory cytokine production. The difference between laboratory cytokine assays in CHS and InCHIANTI subjects may have decreased the ability to detect a true association and metaanalyzed results should be interpreted with great caution. However, effect sizes were consistent in independent study results, as well as the meta-analysis, leading us to believe that this bias did not affect the findings of this study. Although the combined sample size is relatively small for GWAS, the large effect sizes observed suggest that the genetic signals are robust. While some of our findings are consistent with previously reported genetic associations, the signal for serum levels of IL-18 located on chromosome 2 is novel and potentially important in inflammasome-triggered chronic activation of inflammation in older adults. Replication in additional independent cohorts is an important next step,particularly for the replication of the association between chromosome 2 region and IL-18 serum concentrations. Particularly, it would be interesting to test these associations in retrospective cohorts of older adults with known metabolic or cardiovascular diseases characterized by elevated serum IL-1RA and IL-18 levels. Ultimately, molecular studies will encourage a better understanding of the role of NLRC4 in the activation of chronic inflammation in older adults.

\section{Supplementary Material}

Refer to Web version on PubMed Central for supplementary material.

\section{Acknowledgments}

This study was supported by grants R01 AG027236 (Dr. Walston), R01 HL071862 (Dr. Reiner) and by the Johns Hopkins Older Americans Independence Center, P30 AG021334. The Cardiovascular Health Study was supported by contracts HHSN268201200036C, N01-HC-85239, N01-HC-85079 through N01-HC-85086, N01-HC-35129, 
N01 HC-15103, N01 HC-55222, N01-HC-75150, N01-HC-45133, and grant HL080295 from the National Heart, Lung, and Blood Institute (NHLBI), with additional contribution from the National Institute of Neurological Disorders and Stroke (NINDS). Additional support was provided through AG-023629, AG-15928, AG-20098, and AG-027058 from the National Institute on Aging (NIA). CHS genotyping was supported by HL087652. A full list of participating CHS investigators and institutions can be found at http://www.chs-nhlbi.org/pi.htm. The InCHIANTI study baseline (1998-2000) was supported as a "targeted project" (ICS110.1/RF97.71) by the Italian Ministry of Health and in part by the U.S. National Institute on Aging (Contracts: 263 MD 9164 and 263 MD 821336).

\section{Reference List}

1. Singh T, Newman AB. Inflammatory markers in population studies of aging. Ageing Res Rev. 2011; 10(3):319-329. [PubMed: 21145432]

2. Varadhan R, Yao W, Matteini A, et al. A Simple Biologically Informed Inflammatory Index of Two Serium Cytokins Best Predicts All-Cause Mortality over 10 Years in Older Adults. Journal of Gerontology: Medical Science. 2012

3. Dinarello CA. Interleukin 1 and interleukin 18 as mediators of inflammation and the aging process. Am J Clin Nutr. 2006; 83(2):447S-455S. [PubMed: 16470011]

4. Thorand B, Kolb H, Baumert J, et al. Elevated levels of interleukin-18 predict the development of type 2 diabetes: results from the MONICA/KORA Augsburg Study, 1984-2002. Diabetes. 2005; 54(10):2932-2938. [PubMed: 16186395]

5. Evans J, Collins M, Jennings C, et al. The association of interleukin-18 genotype and serum levels with metabolic risk factors for cardiovascular disease. Eur J Endocrinol. 2007; 157(5):633-640. [PubMed: 17984243]

6. Jefferis BJ, Papacosta O, Owen CG, et al. Interleukin 18 and coronary heart disease: prospective study and systematic review. Atherosclerosis. 2011; 217(1):227-233. [PubMed: 21481392]

7. Stenholm S, Koster A, Alley DE, et al. Adipocytokines and the metabolic syndrome among older persons with and without obesity: the InCHIANTI study. Clin Endocrinol (Oxf). 2010; 73(1):55-65. [PubMed: 19878507]

8. Horai R, Nakajima A, Habiro K, et al. TNF-alpha is crucial for the development of autoimmune arthritis in IL-1 receptor antagonist-deficient mice. J Clin Invest. 2004; 114(11):1603-1611. [PubMed: 15578092]

9. Ruggiero C, Cherubini A, Ble A, et al. Uric acid and inflammatory markers. Eur Heart J. 2006; 27(10):1174-1181. [PubMed: 16611671]

10. Tack CJ, Stienstra R, Joosten LA, Netea MG. Inflammation links excess fat to insulin resistance: the role of the interleukin-1 family. Immunol Rev. 2012; 249(1):239-252. [PubMed: 22889226]

11. Nicklin MJ, Barton JL, Nguyen M, FitzGerald MG, Duff GW, Kornman K. A sequence-based map of the nine genes of the human interleukin-1 cluster. Genomics. 2002; 79(5):718-725. [PubMed: 11991722]

12. Wetmore JB, Hung AM, Lovett DH, Sen S, Quershy O, Johansen KL. Interleukin-1 gene cluster polymorphisms predict risk of ESRD. Kidney Int. 2005; 68(1):278-284. [PubMed: 15954918]

13. Benke KS, Carlson MC, Doan BQ, et al. The association of genetic variants in interleukin-1 genes with cognition: findings from the cardiovascular health study. Exp Gerontol. 2011; 46(12):10101019. [PubMed: 21968104]

14. Hwang YS, Jeong M, Park JS, et al. Interleukin-1beta stimulates IL-8 expression through MAP kinase and ROS signaling in human gastric carcinoma cells. Oncogene. 2004; 23(39):6603-6611. [PubMed: 15208668]

15. La E, Rundhaug JE, Pavone A, Fischer SM. Regulation of transcription of the intracellular interleukin-1 receptor antagonist gene by AP-1 in mouse carcinoma cells. Mol Carcinog. 2002; 33(4):237-243. [PubMed: 11933077]

16. Kalina U, Ballas K, Koyama N, et al. Genomic organization and regulation of the human interleukin-18 gene. Scand J Immunol. 2000; 52(6):525-530. [PubMed: 11119255]

17. Koch W, Wolferstetter H, Schatke A, Schomig A, Kastrati A. Interleukin 18 gene variation and risk of acute myocardial infarction. Cytokine. 2011; 56(3):786-791. [PubMed: 22015107] 
18. Melzer D, Perry JR, Hernandez D, et al. A genome-wide association study identifies protein quantitative trait loci (pQTLs). PLoS Genet. 2008; 4(5):e1000072. [PubMed: 18464913]

19. Melzer D, Perry JR, Hernandez D, et al. A genome-wide association study identifies protein quantitative trait loci (pQTLs). PLoS Genet. 2008; 4(5):e1000072. [PubMed: 18464913]

20. He M, Cornelis MC, Kraft P, et al. Genome-wide association study identifies variants at the IL18BCO2 locus associated with interleukin-18 levels. Arterioscler Thromb Vasc Biol. 2010; 30(4): 885-890. [PubMed: 20150558]

21. Tekola AF, Doumatey A, Huang H, et al. Genome-wide associated loci influencing interleukin (IL)-10, IL-1Ra, and IL-6 levels in African Americans. Immunogenetics. 2012; 64(5):351-359. [PubMed: 22205395]

22. de Maat MP, Bladbjerg EM, Hjelmborg JB, Bathum L, Jespersen J, Christensen K. Genetic influence on inflammation variables in the elderly. Arterioscler Thromb Vasc Biol. 2004; 24(11): 2168-2173. [PubMed: 15345506]

23. Fried LP, Borhani NO, Enright P, et al. The Cardiovascular Health Study: design and rationale. Ann Epidemiol. 1991; 1(3):263-276. [PubMed: 1669507]

24. Ferrucci L, Bandinelli S, Benvenuti E, et al. Subsystems contributing to the decline in ability to walk: bridging the gap between epidemiology and geriatric practice in the InCHIANTI study. $\mathrm{J}$ Am Geriatr Soc. 2000; 48(12):1618-1625. [PubMed: 11129752]

25. Bandeen-Roche K, Walston JD, Huang Y, Semba RD, Ferrucci L. Measuring systemic inflammatory regulation in older adults: evidence and utility. Rejuvenation Res. 2009; 12(6):403410. [PubMed: 20041734]

26. Ferrucci L, Corsi A, Lauretani F, et al. The origins of age-related proinflammatory state. Blood. 2005; 105(6):2294-2299. [PubMed: 15572589]

27. Macy EM, Hayes TE, Tracy RP. Variability in the measurement of C-reactive protein in healthy subjects: implications for reference intervals and epidemiological applications. Clin Chem. 1997; 43(1):52-58. [PubMed: 8990222]

28. Purcell S, Neale B, Todd-Brown K, et al. PLINK: a tool set for whole-genome association and population-based linkage analyses. Am J Hum Genet. 2007; 81(3):559-575. [PubMed: 17701901]

29. Li Y, Willer CJ, Ding J, Scheet P, Abecasis GR. MaCH: using sequence and genotype data to estimate haplotypes and unobserved genotypes. Genet Epidemiol. 2010; 34(8):816-834. [PubMed: 21058334]

30. Li Y, Willer C, Sanna S, Abecasis G. Genotype imputation. Annu Rev Genomics Hum Genet. 2009; 10:387-406. [PubMed: 19715440]

31. Willer CJ, Li Y, Abecasis GR. METAL: fast and efficient meta-analysis of genomewide association scans. Bioinformatics. 2010; 26(17):2190-2191. [PubMed: 20616382]

32. Schaid DJ, Rowland CM, Tines DE, Jacobson RM, Poland GA. Score tests for association between traits and haplotypes when linkage phase is ambiguous. Am J Hum Genet. 2002; 70(2):425-434. [PubMed: 11791212]

33. Lamkanfi M, Dixit VM. Inflammasomes and their roles in health and disease. Annu Rev Cell Dev Biol. 2012; 28:137-161. [PubMed: 22974247]

34. Broz P, von MJ, Jones JW, Vance RE, Monack DM. Differential requirement for Caspase-1 autoproteolysis in pathogen-induced cell death and cytokine processing. Cell Host Microbe. 2010; 8(6):471-483. [PubMed: 21147462]

35. Melzer D, Perry JR, Hernandez D, et al. A genome-wide association study identifies protein quantitative trait loci (pQTLs). PLoS Genet. 2008; 4(5):e1000072. [PubMed: 18464913]

36. Frayling TM, Rafiq S, Murray A, et al. An interleukin-18 polymorphism is associated with reduced serum concentrations and better physical functioning in older people. J Gerontol A Biol Sci Med Sci. 2007; 62(1):73-78. [PubMed: 17301041]

37. Tekola AF, Doumatey A, Huang H, et al. Genome-wide associated loci influencing interleukin (IL)-10, IL-1Ra, and IL-6 levels in African Americans. Immunogenetics. 2012; 64(5):351-359. [PubMed: 22205395]

38. Croteau-Chonka DC, Wu Y, Li Y, et al. Population-specific coding variant underlies genome-wide association with adiponectin level. Hum Mol Genet. 2012; 21(2):463-471. [PubMed: 22010046] 
39. Rafiq S, Stevens K, Hurst AJ, et al. Common genetic variation in the gene encoding interleukin-1receptor antagonist (IL-1RA) is associated with altered circulating IL-1RA levels. Genes Immun. 2007; 8(4):344-351. [PubMed: 17443229]

40. Luotola K, Pietila A, Alanne M, et al. Genetic variation of the interleukin-1 family and nongenetic factors determining the interleukin-1 receptor antagonist phenotypes. Metabolism. 2010; 59(10): 1520-1527. [PubMed: 20178882]

41. Reiner AP, Wurfel MM, Lange LA, et al. Polymorphisms of the IL1-receptor antagonist gene (IL1RN) are associated with multiple markers of systemic inflammation. Arterioscler Thromb Vasc Biol. 2008; 28(7):1407-1412. [PubMed: 18451331]

42. Dehghan A, Yang Q, Peters A, et al. Association of novel genetic Loci with circulating fibrinogen levels: a genome-wide association study in 6 population-based cohorts. Circ Cardiovasc Genet. 2009; 2(2):125-133. [PubMed: 20031576]

43. Wassel CL, Lange LA, Keating BJ, et al. Association of genomic loci from a cardiovascular gene SNP array with fibrinogen levels in European Americans and African-Americans from six cohort studies: the Candidate Gene Association Resource (CARe). Blood. 2011; 117(1):268-275. [PubMed: 20978265]

44. van, d; V, Stoeckman, AK.; Wu, G., et al. IL-38 binds to the IL-36 receptor and has biological effects on immune cells similar to IL-36 receptor antagonist. Proc Natl Acad Sci U S A. 2012; 109(8):3001-3005. [PubMed: 22315422]

45. Adzhubei IA, Schmidt S, Peshkin L, et al. A method and server for predicting damaging missense mutations. Nat Methods. 2010; 7(4):248-249. [PubMed: 20354512]

46. Sainz J, Perez E, Gomez-Lopera S, Jurado M. IL1 gene cluster polymorphisms and its haplotypes may predict the risk to develop invasive pulmonary aspergillosis and modulate $\mathrm{C}$-reactive protein level. J Clin Immunol. 2008; 28(5):473-485. [PubMed: 18484169]

47. Dehghan A, Dupuis J, Barbalic M, et al. Meta-analysis of genome-wide association studies in $>80$ 000 subjects identifies multiple loci for C-reactive protein levels. Circulation. 2011; 123(7):731738. [PubMed: 21300955]

48. Carrol ED, Payton A, Payne D, et al. The IL1RN promoter rs4251961 correlates with IL-1 receptor antagonist concentrations in human infection and is differentially regulated by GATA-1. J Immunol. 2011; 186(4):2329-2335. [PubMed: 21248262] 
- We proposed that gene variation predicts changes in IL-18 and IL-1ra serum levels.

- We conducted a genome-wide association scan in prospective cohorts of older adults.

- We characterized robust genetic signals that influence IL-18 and IL1-ra levels.

- We identified SNPs near the NLRC4 gene associated with serum IL-18. 
a)

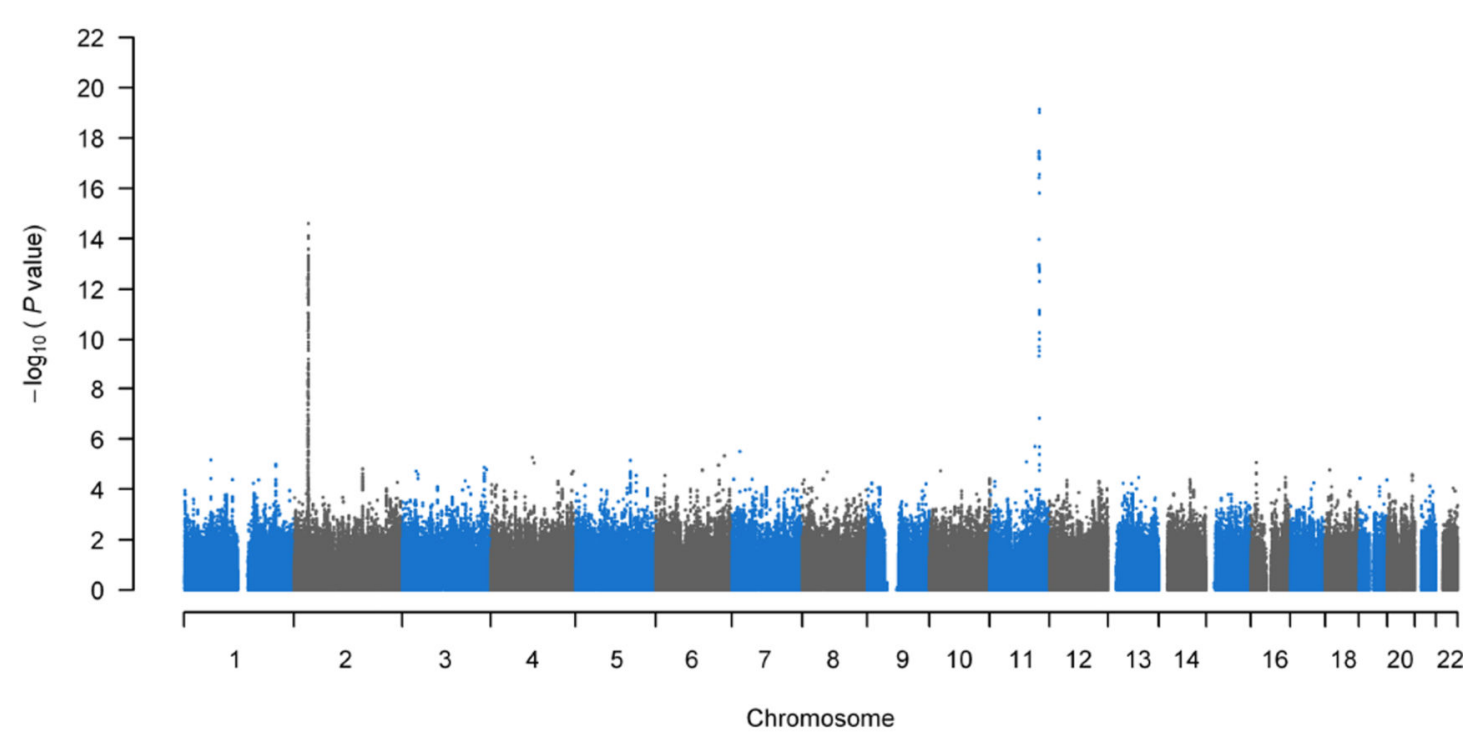

b)

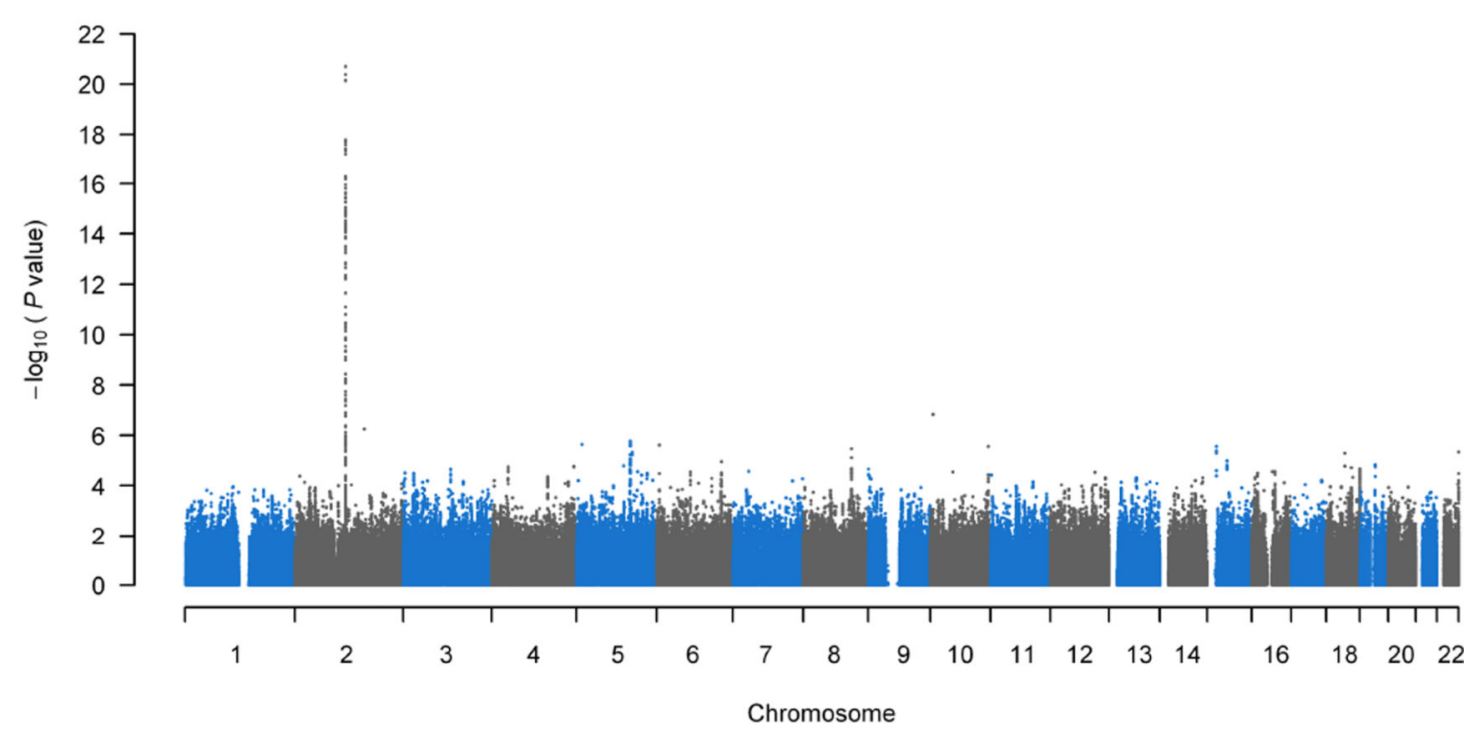

Figure 1.

Manhattan plots from CHS a) IL-18 and b) IL-1ra 


\section{Table 1}

Statistical Power Estimates for InCHIANTI, CHS, and the meta-analyzed CHS-InCHIANTI results

\begin{tabular}{|ccccc|}
\hline $\mathbf{h}^{\mathbf{2}}$ & $\mathbf{7 0 0}$ Subjects & $\begin{array}{c}\mathbf{1 2 0 0} \\
\text { Subjects } \\
\text { (InCHIANTI) }\end{array}$ & $\begin{array}{c}\mathbf{3 2 0 0} \\
\text { Subjects } \\
\text { (CHS) }\end{array}$ & $\begin{array}{c}\text { 4500 Subjects } \\
\text { (Meta-analyzed } \\
\text { sample) }\end{array}$ \\
\hline $\mathbf{1 \%}$ & 0.01 & 0.05 & 0.74 & 0.96 \\
\hline $\mathbf{2 \%}$ & 0.10 & 0.45 & 0.999 & 1 \\
\hline $\mathbf{3 \%}$ & 0.36 & 0.86 & 1 & 1 \\
\hline $\mathbf{4 \%}$ & 0.66 & 0.98 & 1 & 1 \\
\hline $\mathbf{5 \%}$ & 0.87 & 0.99 & 1 & 1 \\
\hline $\mathbf{6 \%}$ & 0.96 & 0.999 & 1 & 1 \\
\hline $\mathbf{7 \%}$ & 0.99 & 1 & 1 & 1 \\
\hline
\end{tabular}


Table 2

Descriptive Statistics for CHS and InCHIANTI

\begin{tabular}{|l|c|c|}
\hline & CHS (n=4,925) & InCHIANTI (n=1,210) \\
\hline IL-1ra (pg/mL), mean(std) & $159.4(36.4)$ & $158.5(127.8)$ \\
\hline IL-18 (pg/mL), mean(std) & $152.4(68.8)$ & $397.0(156.3)$ \\
\hline IL-6 (pg/mL), mean(std) & $4.6(5.1)$ & $2.1(4.0)$ \\
\hline CRP (mg/L), mean(std) & $3.1(2.2)$ & $5.1(9.3)$ \\
\hline Age (years), mean(std) & $71.5(6.4)$ & $68.3(15.5)$ \\
\hline Male, $\mathbf{n}(\%)$ & $2135(43.3)$ & $540(44.6)$ \\
\hline Frailty & & \\
\hline & & $555(48.1)$ \\
\hline Robust, n (\%) & $2214(49.4)$ & $486(42.1)$ \\
\hline Prefrail, n (\%) & $2009(44.8)$ & $114(9.9)$ \\
\hline Frail, n (\%) & $262(5.8)$ & $125(10.8)$ \\
\hline Diabetes n (\%) & $715(14.6)$ & $125(10.8)$ \\
\hline CVD n (\%) & $1238(25.1)$ &
\end{tabular}




\begin{tabular}{|c|c|c|c|c|c|c|c|c|c|c|c|c|c|c|c|c|c|c|c|}
\hline 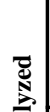 & $\mid \begin{array}{l}2 \\
0 \\
2 \\
2\end{array}$ & 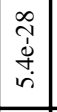 & 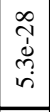 & 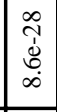 & 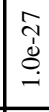 & 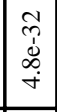 & $\begin{array}{l}\tilde{\jmath} \\
\dot{\jmath} \\
\stackrel{-}{-}\end{array}$ & \begin{tabular}{|l}
$\tilde{J}$ \\
$\dot{d}$ \\
-
\end{tabular} & $\begin{array}{l}\tilde{I} \\
\dot{d} \\
\infty \\
i\end{array}$ & 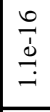 & $\begin{array}{l}\stackrel{0}{0} \\
\stackrel{\dot{b}}{ت}\end{array}$ & 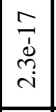 & $\mid \begin{array}{l}\hat{\vec{j}} \\
\hat{i} \\
\hat{i}\end{array}$ & \begin{tabular}{|l}
0 \\
\multirow{u}{u}{} \\
$\tilde{n}$
\end{tabular} & 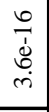 & $\frac{n}{\frac{n}{j}}$ & $\mid \begin{array}{l}n \\
\dot{d} \\
\stackrel{d}{-}\end{array}$ & 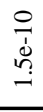 & 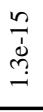 \\
\hline 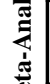 & 鱼 & $\mid \begin{array}{c}\tilde{0} \\
0\end{array}$ & $\begin{array}{l}0 \\
\dot{0}\end{array}$ & ä. & $\stackrel{\Xi}{\circ}$ & $\overrightarrow{0}$ & $\begin{array}{l}\overrightarrow{0} \\
\dot{0}\end{array}$ & 官 & $\stackrel{\Xi}{0}$ & $\stackrel{\Xi}{0}$ & $\tilde{o}_{0}$ & $\overrightarrow{0}$ & $\mid \begin{array}{c}0 \\
\dot{0}\end{array}$ & $\overline{0}$ & $\overline{0}$ & ä. & $\begin{array}{l}\tilde{0} \\
\dot{0}\end{array}$ & ¿. & $\begin{array}{l}\overline{0} \\
0\end{array}$ \\
\hline$\sum^{\circ}$ & $\infty$ & $\stackrel{1}{0}$ & $\stackrel{\simeq}{0}$ & $\begin{array}{l}\bar{Z} \\
i \\
\end{array}$ & $\frac{1}{1}$ & $\stackrel{0}{0}$ & $\stackrel{0}{0}$ & $\stackrel{0}{\circ}$ & $\begin{array}{l}0 \\
0 \\
0\end{array}$ & $\stackrel{\infty}{0}$ & $\stackrel{\infty}{\circ}$ & $\begin{array}{l}\infty \\
0 \\
0\end{array}$ & $\mid \begin{array}{l}\infty \\
0 \\
0\end{array}$ & : & $\stackrel{8}{\circ}$ & $\mid \begin{array}{l}0 \\
0 \\
0\end{array}$ & $\stackrel{a}{0}$ & 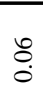 & o. \\
\hline & $\begin{array}{l}1 \\
2 \\
2 \\
2\end{array}$ & 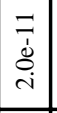 & $\begin{array}{l}= \\
\dot{\delta} \\
\dot{i} \\
\dot{1}\end{array}$ & 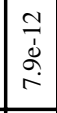 & $\begin{array}{l}= \\
\dot{j} \\
\dot{m}\end{array}$ & $\mid \begin{array}{l}m \\
\\
\grave{r} \\
\end{array}$ & $\begin{array}{l}m \\
\dot{j} \\
\stackrel{-}{-}\end{array}$ & \begin{tabular}{|l|}
$\mathfrak{r}$ \\
$\infty$ \\
$\dot{\delta}$ \\
$i$
\end{tabular} & $\begin{array}{l}n \\
\tilde{d} \\
\end{array}$ & 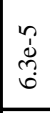 & $\begin{array}{l}n \\
\dot{j} \\
0\end{array}$ & $\begin{array}{l}\stackrel{n}{\dot{v}} \\
\stackrel{r}{\sim}\end{array}$ & \begin{tabular}{|l}
$n$ \\
$\dot{j}$ \\
$\dot{i}$
\end{tabular} & $\begin{array}{l}n \\
\vdots \\
\dot{0} \\
i\end{array}$ & 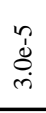 & $\mid \begin{array}{l}n \\
\dot{q} \\
\infty \\
\infty\end{array}$ & $\begin{array}{l}n \\
\dot{j} \\
+\infty \\
\infty\end{array}$ & $\begin{array}{l}\hat{\delta} \\
\stackrel{\delta}{\circ}\end{array}$ & $\frac{7}{0}$ \\
\hline كِّ & 罟 & $\begin{array}{l}\tilde{\delta} \\
\delta \\
0\end{array}$ & $\begin{array}{l}0 \\
\delta \\
0 \\
0\end{array}$ & $\begin{array}{l}\sigma \\
0 \\
0\end{array}$ & $\stackrel{\tilde{\sigma}}{0}$ & 官 & $\overrightarrow{0}$ & $\tilde{0}_{0}$ & $\overline{0}$ & $\overrightarrow{0}_{0}$ & $\stackrel{\vec{o}}{\circ}$ & $\begin{array}{l}\overrightarrow{0} \\
\dot{0}\end{array}$ & $\begin{array}{l}\overrightarrow{0} \\
\end{array}$ & ¿. & $\stackrel{\overline{0}}{0}$ & $\overline{0}$ & $\begin{array}{l}\overrightarrow{0} \\
\dot{0}\end{array}$ & $\stackrel{\overline{0}}{\circ}$ & $\overline{0}$ \\
\hline & $\infty$ & $\stackrel{1}{0}$ & $\dddot{7}$ & $\because$ & $\because$ & $\stackrel{0}{0}$ & $\stackrel{0}{0}$ & 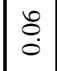 & $\stackrel{0}{\circ}$ & 苂 & $\stackrel{0}{\circ}$ & $\stackrel{0}{0}$ & 号 & $\stackrel{8}{0}$ & $\stackrel{0}{0}$ & 菅 & : & $\stackrel{\Delta}{0}$ & $\stackrel{0}{0}$ \\
\hline & $\begin{array}{l}2 \\
2 \\
2 \\
2\end{array}$ & \begin{tabular}{|l|}
$\infty$ \\
$\frac{1}{d}$ \\
$\stackrel{m}{2}$
\end{tabular} & $\begin{array}{c}\infty \\
\frac{\infty}{j} \\
\dot{j} \\
\dot{m}\end{array}$ & $\mid \begin{array}{l}\infty \\
\vec{j} \\
\dot{j} \\
0 \\
\end{array}$ & 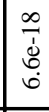 & 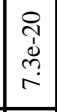 & $\mid \begin{array}{c}\tilde{1} \\
\grave{d} \\
\stackrel{0}{\alpha} \\
\mid\end{array}$ & $\mid \begin{array}{l}m \\
\stackrel{2}{\Delta} \\
\stackrel{\sim}{+}\end{array}$ & $\frac{m}{\dot{s}}$ & $\begin{array}{l}n \\
\bar{d} \\
\dot{\alpha} \\
\infty\end{array}$ & $\begin{array}{l}n \\
\\
\\
a\end{array}$ & $\mid \begin{array}{l}n \\
n \\
\dot{1} \\
n \\
i \\
\end{array}$ & $\mid \begin{array}{l}n \\
\frac{1}{j} \\
\dot{j} \\
r\end{array}$ & $\mid \begin{array}{l} \pm \\
\dot{j} \\
\tilde{n} \\
\sigma\end{array}$ & $\frac{ \pm}{d}$ & $\mid \begin{array}{c}m \\
\dot{j} \\
\dot{j} \\
-\end{array}$ & $\begin{array}{c}m \\
\dot{j} \\
\stackrel{j}{+} \\
\dot{r}\end{array}$ & $\begin{array}{l}\hat{\dot{d}} \\
\text { i. }\end{array}$ & $\begin{array}{c}\frac{m}{1} \\
\dot{j} \\
m \\
m\end{array}$ \\
\hline 记 & 岳 & $\begin{array}{l}\overrightarrow{0} \\
\dot{0}\end{array}$ & $\vec{\vdots}$ & $\bar{\sigma}$ & $\tilde{O}_{0}^{0}$ & 苂 & $\begin{array}{l}\overrightarrow{0} \\
\end{array}$ & $\begin{array}{l}\dot{0} \\
0\end{array}$ & $\overline{0}$ & $\overrightarrow{0}$ & $\bar{o}_{0}$ & $\begin{array}{l}\overrightarrow{0} \\
0\end{array}$ & $\begin{array}{l}\overrightarrow{0} \\
0\end{array}$ & $\ddot{0}$ & $\overrightarrow{0}$ & $\overline{0}$ & $\begin{array}{l}0 \\
0\end{array}$ & $\bar{\sigma}_{0}$ & $\overline{0}$ \\
\hline & $\infty$ & $\begin{array}{c}7 \\
0\end{array}$ & $\exists$ & $=$ & $=$ & $\stackrel{\circ}{\circ}$ & $\stackrel{0}{0}$ & ơ. & Oे. & $\mid \begin{array}{l}0 \\
0 \\
i \\
i\end{array}$ & oे. & $\stackrel{0}{\circ}$ & 官 & oे & $\stackrel{\partial}{0}$ & $\begin{array}{l}\infty \\
0 \\
0\end{array}$ & $\stackrel{\partial}{0}$ & so. & :े \\
\hline & $\bar{\Sigma}$ & 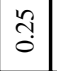 & 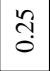 & $\begin{array}{l}2 \\
0 \\
0\end{array}$ & đั & $\stackrel{\infty}{+\infty}$ & $\stackrel{\infty}{+}$ & รั. & I̊ & q & $\begin{array}{l}7 \\
0 \\
0\end{array}$ & $\begin{array}{l}\exists \\
0\end{array}$ & F. & 吕 & fo & 京 & $\begin{array}{l}q \\
0 \\
0\end{array}$ & గn: & $\begin{array}{c}\infty \\
\stackrel{m}{0} \\
0\end{array}$ \\
\hline & $\frac{\pi}{2}$ & 5 & $\mid \begin{array}{l}0 \\
ن \\
\end{array}$ & $\stackrel{0}{H}$ & $\stackrel{U}{\leftrightarrow}$ & $\stackrel{U}{H}$ & $\underset{H}{U}$ & U & $\stackrel{\varrho}{\digamma}$ & $\stackrel{\bigcup}{\vartheta}$ & $\stackrel{\bigcup}{\vartheta}$ & 5 & $\mathbb{U}$ & $\stackrel{\mho}{\digamma}$ & $\mathbb{J}$ & 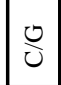 & $\mathbb{U}$ & 5 & 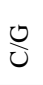 \\
\hline & 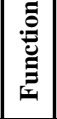 & 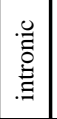 & 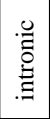 & & & 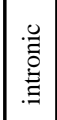 & 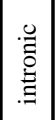 & 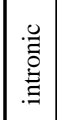 & 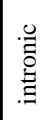 & 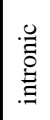 & 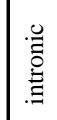 & & & 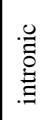 & 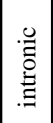 & \begin{tabular}{|l} 
号 \\
昜
\end{tabular} & 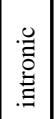 & 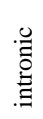 & 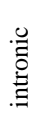 \\
\hline & 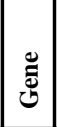 & $\stackrel{\infty}{\stackrel{\Xi}{\Xi}}$ & $\stackrel{\infty}{\exists}$ & 1 & & $\begin{array}{l}\tilde{\delta} \\
\delta \\
\mathscr{\infty}\end{array}$ & $\underset{ర}{\tilde{D}}$ & 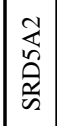 & 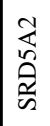 & 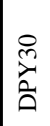 & 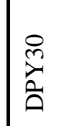 & & & $\begin{array}{l}5 \\
\bar{n} \\
\text { के }\end{array}$ & $\mid \begin{array}{l}5 \\
\frac{5}{2} \\
\hat{n}\end{array}$ & 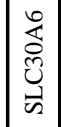 & 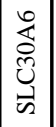 & 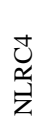 & $\begin{array}{l}\frac{0}{n} \\
\frac{a}{z}\end{array}$ \\
\hline & 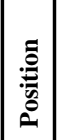 & 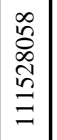 & 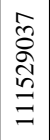 & 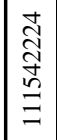 & 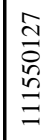 & 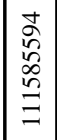 & 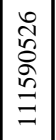 & 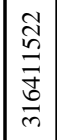 & 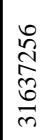 & $\begin{array}{l}2 \\
2 \\
n \\
2 \\
\bar{n}\end{array}$ & $\begin{array}{l}\overrightarrow{\widehat{\sigma}} \\
\hat{\sigma} \\
\bar{d} \\
\text { d. }\end{array}$ & 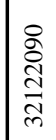 & 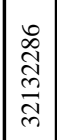 & 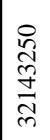 & 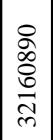 & 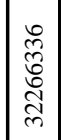 & 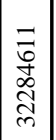 & 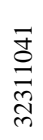 & 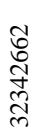 \\
\hline & $\stackrel{\hat{z}}{\omega}$ & 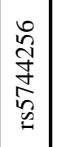 & 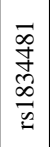 & 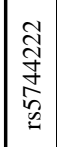 & | & 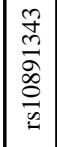 & 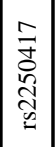 & 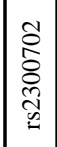 & 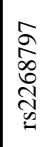 & 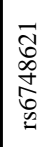 & 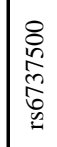 & 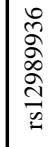 & 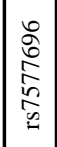 & 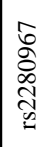 & \begin{tabular}{|l}
0 \\
0 \\
0 \\
0 \\
0 \\
0.02
\end{tabular} & 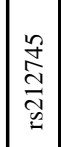 & 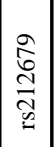 & $\begin{array}{l}\frac{m}{\sqrt{d}} \\
\underset{w}{N}\end{array}$ & 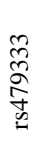 \\
\hline & $\tilde{z}$ & $=$ & $=$ & $=$ & $=$ & $=$ & $=$ & a & $\mathrm{N}$ & $a$ & $\mathrm{~N}$ & N & $A$ & $a$ & 4 & $\alpha$ & $\sim$ & $\alpha$ & $\mathrm{N}$ \\
\hline
\end{tabular}




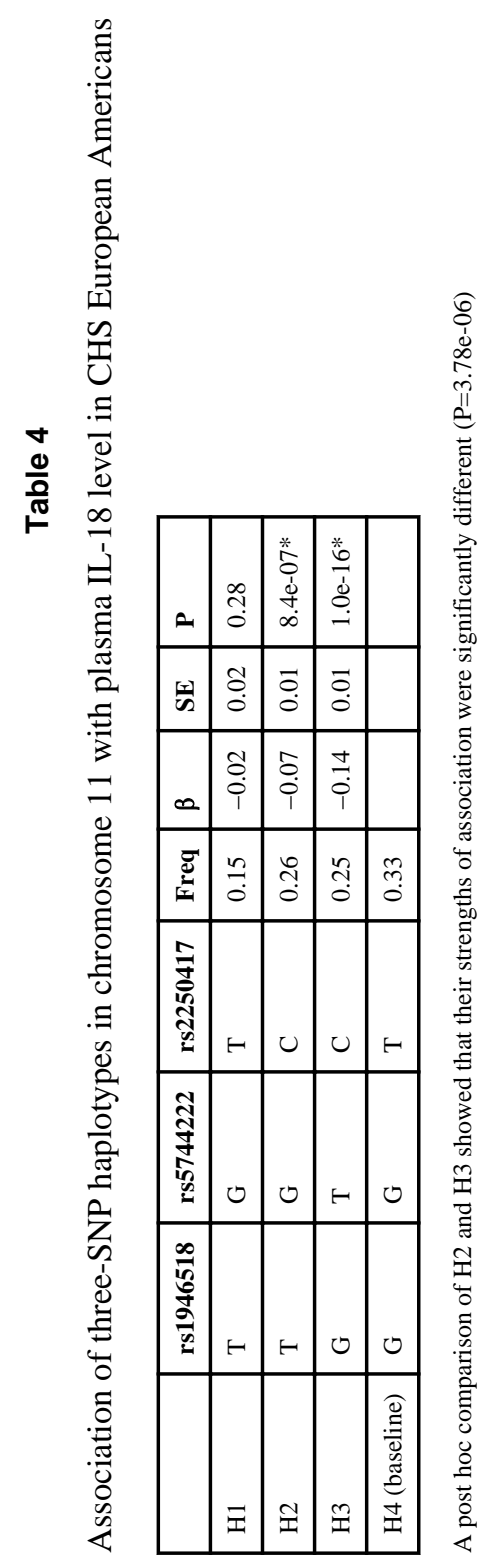

Cytokine. Author manuscript; available in PMC 2015 January 01. 
(n)

$\frac{\sqrt{0}}{2}$

\begin{tabular}{|c|c|c|c|c|c|}
\hline 2 & 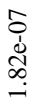 & $\begin{array}{l}\stackrel{8}{0} \\
\stackrel{8}{0} \\
\stackrel{0}{0}\end{array}$ & $\stackrel{m}{0}$ & 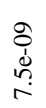 & , \\
\hline 颁 & $\stackrel{0}{0}$ & $\underset{0}{0}$ & $\stackrel{d}{\circ}$ & $\underset{\circ}{0}$ & \\
\hline$n$ & $\frac{0}{0}$ & $\frac{0}{0}$ & $\begin{array}{l}\text { o̊ } \\
\stackrel{i}{i}\end{array}$ & $\begin{array}{l}\infty \\
\stackrel{0}{0} \\
\stackrel{+}{1}\end{array}$ & \\
\hline 胥 & $\stackrel{1}{\circ}$ & $\stackrel{\overbrace{}}{0}$ & $\stackrel{\circ}{0}$ & $\stackrel{\hat{N}}{0}$ & $\stackrel{f}{0}$ \\
\hline 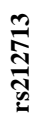 & $u$ & $H$ & U & U & $H$ \\
\hline 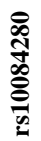 & ט & ט & $\varangle$ & ט & ט \\
\hline 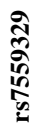 & $u$ & U & $H$ & $\mapsto$ & $H$ \\
\hline & $\bar{\Xi}$ & I & I & 声 & 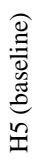 \\
\hline
\end{tabular}

Cytokine. Author manuscript; available in PMC 2015 January 01. 


\begin{tabular}{|c|c|c|c|c|c|c|c|}
\hline$\cong$ & 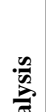 & $\begin{array}{l}2 \\
\vdots \\
\vdots \\
\vdots\end{array}$ & 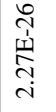 & 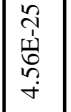 & 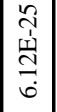 & 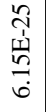 & 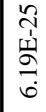 \\
\hline & 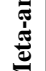 & $\begin{array}{ll}5 \\
6\end{array}$ & $\bar{\Xi}$ & $\stackrel{\overrightarrow{0}}{\circ}$ & $\overrightarrow{0}$ & $\overrightarrow{0}$ & \\
\hline Z & & $\approx$ & $\stackrel{m}{0}$ & $\stackrel{1}{0}$ & $\frac{m}{0}$ & $\stackrel{m}{0}$ & $\stackrel{m}{0}$ \\
\hline 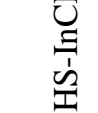 & $\Xi$ & 定 & $\begin{array}{l}n \\
\text { w } \\
\text { in }\end{array}$ & 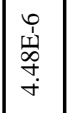 & 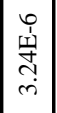 & 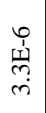 & $\begin{array}{l}0 \\
\text { H્d } \\
\text { ते }\end{array}$ \\
\hline & 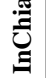 & 된 & $\stackrel{0}{0}$ & $\stackrel{\stackrel{\leftrightarrow}{0}}{\circ}$ & $\begin{array}{c}0 \\
\delta \\
0\end{array}$ & $\begin{array}{l}\tilde{O} \\
\dot{0} \\
\dot{0}\end{array}$ & Oे \\
\hline & & $\infty$ & $=$ & $\overline{0}$ & $\because$ & $=$ & $\stackrel{7}{0}$ \\
\hline 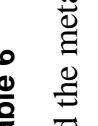 & & $\begin{array}{l}1 \\
\\
\vdots \\
\vdots\end{array}$ & $\begin{array}{l}\vec{T} \\
\text { 山⿱山兀 } \\
\stackrel{i}{i}\end{array}$ & 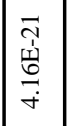 & 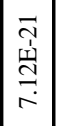 & $\begin{array}{l}\vec{T} \\
1 \\
\infty \\
\infty \\
\infty \\
0\end{array}$ & 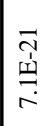 \\
\hline & Uే & 国 & $\bar{\circ}$ & $\overrightarrow{\dot{O}}$ & $\overline{0}$ & $\bar{o}$ & $\tilde{\sigma}_{0}$ \\
\hline 岕 & & $\infty$ & $\frac{U}{0}$ & $\stackrel{m}{0}$ & $\frac{m}{0}$ & $\stackrel{m}{0}$ & $\stackrel{9}{0}$ \\
\hline & & $\sum_{2}^{\frac{\pi}{2}}$ & f̊ & $\stackrel{\infty}{\stackrel{\infty}{0}}$ & $\begin{array}{l}J \\
0\end{array}$ & $\begin{array}{l}J \\
0\end{array}$ & 守 \\
\hline & & $\begin{array}{l}\tilde{z} \\
\mathrm{z}\end{array}$ & $\begin{array}{l}0 \\
\dot{4}\end{array}$ & É & $\begin{array}{l}0 \\
\dot{i}\end{array}$ & $\underset{H}{U}$ & $\stackrel{U}{O}$ \\
\hline$\frac{\stackrel{0}{0}}{\frac{\pi}{\pi}}$ & & 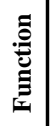 & 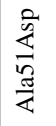 & 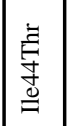 & & & \\
\hline 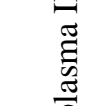 & & 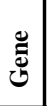 & $\begin{array}{l}\frac{O}{x} \\
\stackrel{ }{J}\end{array}$ & $\underset{\mathrm{O}}{\stackrel{\mathrm{O}}{\mathrm{I}}}$ & ' & ' & . \\
\hline $\begin{array}{l}\overrightarrow{0} \\
\stackrel{0}{0} \\
0\end{array}$ & & 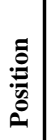 & 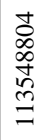 & \begin{tabular}{|l}
$\infty$ \\
$\infty$ \\
$\infty$ \\
$\infty$ \\
$\infty$ \\
$\varrho$ \\
$ٍ$
\end{tabular} & 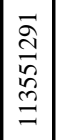 & 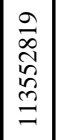 & 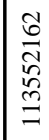 \\
\hline 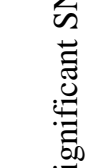 & & $\sum_{\infty}$ & 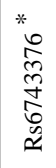 & 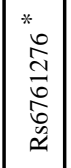 & 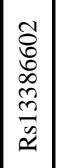 & 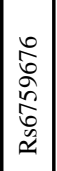 & 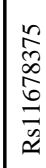 \\
\hline$\stackrel{0}{\circ}$ & & $\bar{z}$ & N & $\mathrm{N}$ & N & $\sim$ & v \\
\hline
\end{tabular}




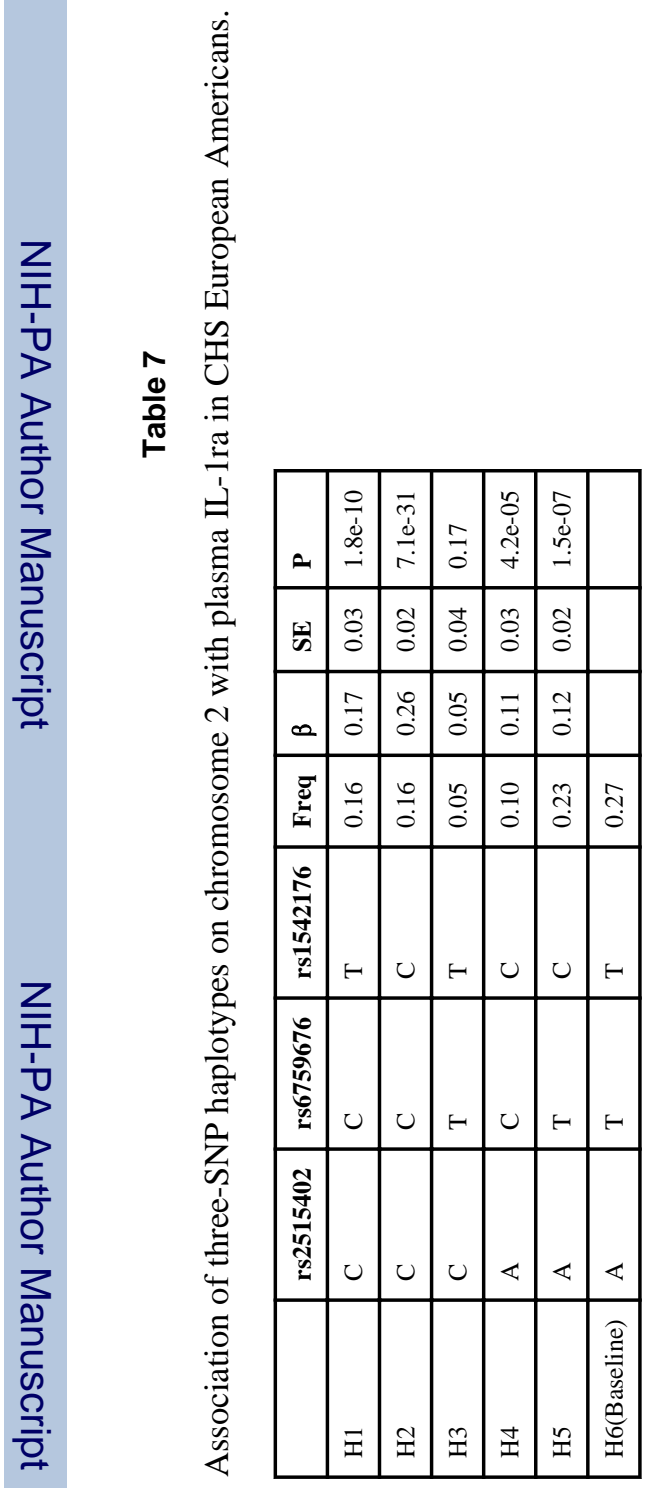

Cytokine. Author manuscript; available in PMC 2015 January 01. 